Leverkus A.B., Thorn S., Lindenmayer D.B., Pausas J.G. 2020. Wildfires debate needs science, not politics. Science 370 (6515): 416-417. https://doi.org/10.1126/science.abf1326

\title{
Wildfire debate needs science, not politics
}

The causes of unprecedented wildfires and their impacts on all forested continents are increasingly the subject of discussion. Proper understanding and management of wildfires are crucial to safeguard human lives and to achieve the United Nations' target of "halting and reversing the degradation of ecosystems worldwide" (1). However, the insights obtained from scientific research are largely off the public radar compared with the lighthearted, but often biased, opinions of politicians [e.g., $(2,3)]$. This is wrongly giving the public the impression that we understand little about wildfires and that intensifying wildfire regimes are a surprise. Decades of research, especially after major wildfires such as the 1988 Yellowstone fires (4) and 2009 southern Australian wildfires (5, 6), have created a vast body of knowledge that politicians are disregarding in favor of opinions. To address these increasingly destructive wildfires, the public debate and resulting policy response must be based on science. Historically, neglecting the role of fire in ecosystems and as a positive driver of biodiversity has produced policies that lead to more fire and ecosystem degradation. Widespread fire suppression has produced landscapes with high fuel loads that exacerbate future fires (4). Removing burnt trees in the name of restoration has impaired the recovery of ecosystem functions and biodiversity (7).

Creating even-aged, monospecific conifer plantations for silviculture has increased fire spread and imperiled regeneration potential (8).

There is considerable scientific consensus on the importance of fire for ecosystems, species evolution, and society (9), as well as on the feedbacks between human land use, changes in wildfire regimes, ecosystem responses, and impacts on human society $(4,5,10)$. We have also learned that climate change interacts with wildfires in multiple ways, for instance by extending the fire season and increasing the frequency of dry years (11). Recent wildfires in Australia, California, and South America exemplify how protracted drought magnifies fire propagation and intensity, leads to fire spreading to nonflammable ecosystems, increases smoke that impairs human health, and undermines the capacity of ecosystems to recover $(10,12)$. Scientific research has promoted policies for a healthier coexistence with fire [e.g., $(4,5,10)]$, including the use of prescribed fire to simulate natural processes and the creation of heterogeneous landscapes in restoration programs to enhance regeneration in case of fire.

Wildfires and droughts will likely transform landscapes and our relationships with them. Whereas research generates knowledge and helps identify new policies to deal with wildfires, recent public debates politicize their causes and consequences by blaming political opponents. These distracting arguments risk setting back the policy advances that have already been made. We advocate a stronger scientific platform to inform public debates about wildfires. Greater promotion of science can improve understanding and management of the ecosystems that face intensifying fire regimes globally.

Alexandro B. Leverkus ${ }^{1,2 *}$, Simon Thorn ${ }^{3}$, David B. Lindenmayer ${ }^{4}$, Juli G. Pausas ${ }^{5}$

1 Departamento de Ecología, Facultad de Ciencias, Universidad de Granada, 18071, Granada. 2 Laboratorio de Ecología, Instituto Interuniversitario de Investigación del Sistema Tierra en Andalucía (IISTA), Universidad de Granada, 18006, Granada, Spain. 3 Field Station Fabrikschleichach, Department of Animal Ecology and Tropical Biology, Biocenter, Universität Würzburg, 97070 Würzburg, Germany. 4 Fenner School of Environment and Society, Australian National University, Canberra, ACT 2601, Australia.

5 Centro de Investigaciones sobre Desertificación (CIDE-CSIC), 46113 Montcada, Valencia, Spain. ${ }^{*}$ Corresponding author. Email: leverkus@ugr.es 


\section{REFERENCES AND NOTES}

1. J. Fischer et al., Trends Ecol. Evol. doi.org/10.1016/j.tree.2020.08.018 (2020).

2. P. Baker et al., "As Trump again rejects science, Biden calls him a 'climate arsonist,"' The New York Times (2020).

3. H. McKay, "Climate change or poor policy? As Australia's wildfires see some relief, blame game ascends," Fox News (2020).

4. M. G. Turner et al., Front. Ecol. Environ. 1, 351 (2003).

5. M. A. Moritz et al., Nature 515, 58 (2014).

6. C. Taylor et al., Conserv. Lett. 7, 355 (2014).

7. A. B. Leverkus et al., Front. Ecol. Environ. 18, 391 (2020).

8. J. R. Thompson et al., Proc. Natl. Acad. Sci. U.S.A. 104, 10743 (2007).

9. J. G. Pausas, J. E. Keeley, Front. Ecol. Environ. 17, 289 (2019).

10. B. A. Wintle et al., Trends Ecol. Evol. 35, 753 (2020).

11. A. L. Westerling et al., Science 313, 940 (2006).

12. N. J. Enright et al., Front. Ecol. Environ. 13, 265 (2015). 